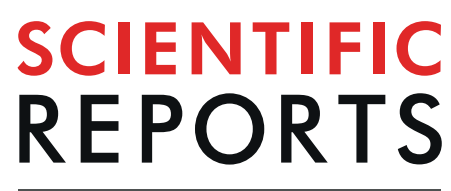

natureresearch

\title{
TiCrN-TiAIN-TiAISIN-TiAISiCN multi-layers utilized to increase tillage tools useful lifetime
}

\author{
Shahab Sharifi Malvajerdi ${ }^{1}$, Ahmad Sharifi Malvajerdi2 ${ }^{2 *}$, Majid Ghanaatshoar ${ }^{1}$, \\ Morteza Habibi ${ }^{3} \&$ Hassan Jahdi ${ }^{4}$
}

For the first time, a hard wear-resistant multi-layer of TiCrN-TiAIN-TiAISiN-TiAISiCN was deposited on carbon steel CK45-based tillage tools to increase their useful lifetime. The layers were deposited by using an arc-PVD method without post-annealing procedures. XRD and EDX data indicated that TiCrN, TiAIN, TiAISiN, and TiAISiCN formed individually and as a multi-layer of high-quality crystalline layers with mostly cubic structures. The studies on the multi-layers coating morphology, roughness and hardness gave reasonable results as a roughness of $35 \mathrm{~nm}$ and a hardness of $32.2 \mathrm{GPa}$. The coated sweep duck blade tillage tools were tested on the field along with a soil bin to obtain their wear behavior at different traveling distances. The draft force of all blades showed promising results. As the coated layers were worn off, their draft force increased. In comparison with single-layer coatings, the multi-layer structure demonstrated an increase in the useful lifetime of the blades.

Titanium-based composites have been of interest of researchers due to their suitable low friction coefficient, high thermal stability, and resistance to oxidation and wear ${ }^{1,2}$. These characteristics have made these materials good candidates for hard coatings to increase the lifetime of instruments utilized for harsh environments ${ }^{3,4}$. Most recently, single layer composite coatings such as TiAlN, TiAlSiN, and TiAlSiCN have been investigated for their well-improved mechanical properties compared to TiN coatings ${ }^{5-8}$. Multi-layer coatings have also gained researchers' interest due to their advantages to single layer coatings ${ }^{9-12}$. Durmaz and Yildiz exhibited high-quality TiAlN coatings which had high wear resistance ${ }^{13}$. Even more, research on TiAlSiN coatings has proved suitability of this composite for anti-wear coating applications ${ }^{14,15}$. A research conducted by Shizhi et al. revealed that by adding $\mathrm{Si}(10-15 \%)$ to TiN will form TiSiN thin films leading to layers with higher hardness than $\mathrm{TiN}^{16}$. Other studies also proved that the presence of $\mathrm{Si}$ in TiN has a significant role in achieving very high hardness compound with better wear resistance ${ }^{17}$. These line-of-ceramic composites have proven to be well applied to high-temperature resistance turbine and aircraft engine blades ${ }^{18,19}$, high resistance to wear for dry cutting tools ${ }^{20-23}$, and other coating applications for molds and $\operatorname{dies}^{24}$, plowshares ${ }^{25}$ and tillage tools ${ }^{26}$. The utilized deposition method plays the key important role in achieving high-quality crystalline layers. TiN-based materials have been deposited by many different techniques over the past years. To name a few, Magnetron sputtering ${ }^{27-32}, \mathrm{CVD}^{33,34}$, PECVD $^{35}$, multi-purpose plasma immersion ion implantation ${ }^{8,36,37}$, Plasma focus ${ }^{38}$, PVD $^{39,40}$ and arc-PVD ${ }^{41-44}$.

The arc-PVD method is able to form high-quality thin films at low temperatures. The PVD method has been employed to grow many multi-refractory metal compositions for wear, thermal and corrosion resistance applications. For instance, TiAlSiN thin films were deposited by Yu, et al. ${ }^{45}$ who studied the hardness of the layers by changing the $\mathrm{Si}$ content ratio. This material was also deposited by $\mathrm{Li}$, et al. ${ }^{35}$. Sui, et al. ${ }^{7}$ research on TiAlN-TiAlSiN double layers also revealed a high level of hardness of the coated tools for cutting applications. Along with research conducted on TiAlSiN, TiAlSi ${ }^{46}$, TiAlN ${ }^{30,47-50}$ and $\mathrm{TiN}^{-\mathrm{TiAlN}^{44}}$ multi-layers have also been deposited by arc-PVD method, which have shown promising mechanical properties. For many years, researchers investigated simple single layer coatings to increase wear and oxidation resistance of cutting tools. Nowadays, studies on hardness, wear, and corrosion resistance are being conducted on more complex and nanocomposite multi-layers to obtain a better performance. Recent investigations on TiAlSiCN multi-layers ${ }^{51-53}$ have shown

\footnotetext{
${ }^{1}$ Laser and Plasma Research Institute, Shahid Beheshti University, G. C. Evin, Tehran, 1983963113, Iran. ${ }^{2}$ Agricultural Engineering Research Institute, Agricultural Research, Education and Extension Organization (AREEO), Karaj, Iran. ${ }^{3}$ Energy Engineering and Physics Department, Amirkabir University of Technology, Tehran, 158754413, Iran. ${ }^{4}$ Sevin Plasma Surface Engineering Co., Isfahan Science and Technology town, Isfahan, Iran. *email: a.sharifi@areeo.ac.ir
} 
their potential to be applied upon cutting tools to resist high temperature, corrosion and wear, and eventually to increase the useful lifetime of the tools.

One of the hardening applications of thin film deposition is in agriculture, where wear resistant thin films are deposited on tillage tools to obtain better performance and longer lifetime. Tillage tools are the core soil engaging implements which confront high abrasive wear. The processes by which tillage tools wear evidently include impact, abrasion and chemical actions ${ }^{54}$. Sweep blades are the most exploited soil preparation tools which are used on the combined tillage implements. Tillage tools should be strong enough to resist impact and wear and to work in hard soil conditions ${ }^{54}$. The case of single ceramic composite coated layers has been previously investigated to reduce wear ${ }^{1,55}$. In our previous research on TiN single layer coating, we were able to obtain resealable results in increasing the lifetime of sweep duck blades ${ }^{1}$. Some of other hardening techniques applied to tillage tools are alumina ceramic coatings ${ }^{56}$, hard facing ${ }^{57}$, plasma restoration and hardening ${ }^{58}$, carbo-vibro-arc hardening method ${ }^{59}$, and hot stamping processes ${ }^{60}$.

In this research, we aim to deposit TiCrN-TiAlN-TiAlSiN-TiAlSiCN multi-layer for the first time, and eventually use them to increase the useful life of sweep duck blade tillage tools. With the procedure of stacking four different layers with similar crystal structures, we aim to introduce a multi-layer with higher wear resistance, hardness and longer lifetime than single layer $\mathrm{TiN}^{1}$. The sweep duck blades (carbon steel CK45) will be coated with TiCrN, TiAlN, TiAlSiN, TiAlSiCN layers using an arc-PVD system with no post-annealing process, before or after the deposition. The first layer, TiCrN, is used as a base layer for other layers with higher hardness to be able to be deposited on top of the carbon steel CK45. The multi-layer has been designed in a way that the hardness of the layers increases from the bottom to the top. The experiments on the coated blades will be carried out at the laboratory and real field conditions to obtain more detailed results for both researchers and manufacturers. In order to examine the performance of the coating, the blades are sent to loamy condition soil. They are tested at four different traveling distances by a tractor, and subsequently, they are tested in a soil bin laboratory condition to measure their draft force. Then, samples from the blades are taken apart to be studied on. Scanning electron microscopy (SEM) and atomic force microscopy (AFM) are employed to study the surface morphology and topology of the blades before and after the field experiment. Energy dispersive X-ray spectroscopy (EDX), and $\mathrm{X}$-ray diffraction (XRD) are exploited to indicate the elements and the crystallinity of the thin films. Additionally, the surface hardness and its roughness are studied by a Vickers hardness monitor and a profilometer. We employ a penetrologger to measure soil mechanical resistance. Soil moisture content is obtained using an oven along with soil texture and chemical properties which are investigated by EC meter, $\mathrm{pH}$ meter, Anion-Cation spectrophotometer, and a hydrometer.

\section{Results}

XRD. XRD patterns of all individual layers and the whole multi-layer are shown in Fig. 1. The XRD data indicated that mostly cubic structures of the materials were formed along with only a few hexagonal structures. In the first layer (TiCrN), two main crystal structures formed; c-TiN (111), (200), (220), (311), (222), and c-TiCrN (111), (200), and (220). According to Fig. 1a there are also other peaks which belong to $\mathrm{Fe}, \mathrm{Fe}_{2} \mathrm{~N}$, and $\mathrm{FeTi}$ through Ti and $\mathrm{N}$ bonding to the Fe atoms of the substrate. The second layer, TiAlN, had three crystal structures; c-TiN with (111), (220), and (311) peaks, h-TiAlN with (105), (106), (202), and (206) peaks, and c-AlN with (200) and (220) peaks (Fig. 1b). Due to the XRD pattern in Fig. 1c, h-TiAlN $\{(103),(105)$, and (206) $\}$, c-TiN $\{(200)$, and (220) $\}$, and $\mathrm{h}-\mathrm{Si}_{3} \mathrm{~N}_{4}\{(114),(106)$, and (326) $\}$ are crystal structures that formed in the third layer, TiAlSiN. XRD of the final layer TiAlSiCN indicated three structures (see Fig. 1d). They are c-TiCN (111) and (220) planes, c-TiN with (200) plane, and c-AlN with (200) and (220) planes. Figure 1e shows the XRD of the multi-layer by which many peaks from all 4 layers were detected. They are c-TiCN with (111), c-TiN (200), and (220), c-AlN (200), $\mathrm{h}-\mathrm{Si}_{3} \mathrm{~N}_{4}$ (106), and h-TiAlN (105), and (206). The XRD data was processed by an Xpert High Score Plus software. The corresponding data sheet reference codes are 01-087-0631 for c-TiN, 01-070-2981 for c-TiCrN, 01-089-4185 for Fe, 03-065-7743 for FeTi, 00-006-0656 for $\mathrm{Fe}_{2} \mathrm{~N}, 01-080-2286$ for h-TiAlN, 00-046-1200 for c-AlN, 01-0792011 for $\mathrm{h}-\mathrm{Si}_{3} \mathrm{~N}_{4}$, and 01-076-2484 for c-TiCN.

All crystallite sizes were calculated from full width of half maximum (FWHM) of the XRD peaks by using the Debye-Scherrer equation $(\tau=K \lambda / \beta \cos \theta)^{61,62}(\tau$ is the size of the crystallite, $\mathrm{K}$ is Scherrer constant $0.94, \lambda$ is the X-ray wavelength which in this case is $1.54 \AA$ produced by a copper pole, $\beta$ is $\Delta(2 \theta)$ (FWHM) of the XRD peaks, and $\theta$ represents the angles where the peaks are positioned $\left.{ }^{63}\right)$. The crystallite sizes of the crystal structures formed in the bottom layer were calculated to be $30 \mathrm{~nm}$ for c-TiN and $30 \mathrm{~nm}$ for c-TiCrN, in TiAlN layer; $12 \mathrm{~nm}$ for c-TiN, $6.5 \mathrm{~nm}$ for h-TiAlN, and $22 \mathrm{~nm}$ for c-AlN, in the third layer, TiAlSiN; $9.8 \mathrm{~nm}$ for c-TiN, $11.1 \mathrm{~nm}$ for $\mathrm{h}$-TiAlN, and $22.73 \mathrm{~nm}$ for $\mathrm{h}-\mathrm{Si}_{3} \mathrm{~N}_{4}$, and in the fourth layer (TiAlSiCN) crystallite sizes where $6.47 \mathrm{~nm}$ for c-TiN, $6.14 \mathrm{~nm}$ for c-TiCN, and $16.7 \mathrm{~nm}$ for c-AlN. The crystallite sizes were also calculated from the XRD data of the multi-layer that were $5.66 \mathrm{~nm}$ for c-TiN, $11.11 \mathrm{~nm}$ for c-TiCN, $15.2 \mathrm{~nm}$ for c-AlN, $16.65 \mathrm{~nm} \mathrm{for} \mathrm{h-Si}{ }_{3} \mathrm{~N}_{4}$, and $12.91 \mathrm{~nm}$ for h-TiAlN.

EDX and Line scan. The elements of each individual layer and their quantification were obtained by EDX cross-sectional spectrum (Fig. 2). This set of data backs up the XRD patterns to conclude that the TiCrN, TiAlN, TiAlSiN and TiAlSiCN layers have been perfectly formed. Figure $2 \mathrm{a}$ shows the element count of the first layer, $\mathrm{TiCrN}$, where the atomic weight of $\mathrm{Ti}$ and $\mathrm{Cr}$ elements match almost at 50:50 ratio as the deposition procedure took place with the same rate of deposition for both materials. In Fig. 2b, EDX spectrum reveals Ti, Cr, $\mathrm{Al}$, and $\mathrm{N}$ atoms with $1 \%$ atomic $\mathrm{Al}$ amount. The $\mathrm{Cr}$ detected in this layer has been originated from the first layer, shown in cross-sectional image. Moreover, the Fe in the first two layers is originated from the substrate. Therefore, the ratio of $\mathrm{Al}$ to $\mathrm{Ti}$ is enough to form TiAlN. The third layer EDX quantification in Fig. 2c indicates Ti and N 50:50 ratio along with $4 \% \mathrm{Al}$ and $0.5 \% \mathrm{Si}$. Finally, the elements of TiAlSiCN layer were observed to be $10 \% \mathrm{Ti}, 23 \% \mathrm{C}, 2 \% \mathrm{Al}$, and $0.6 \% \mathrm{Si}$ (Fig. 2d). Along with the single layer EDX a Line scan of all layers was obtained to detect all elements 


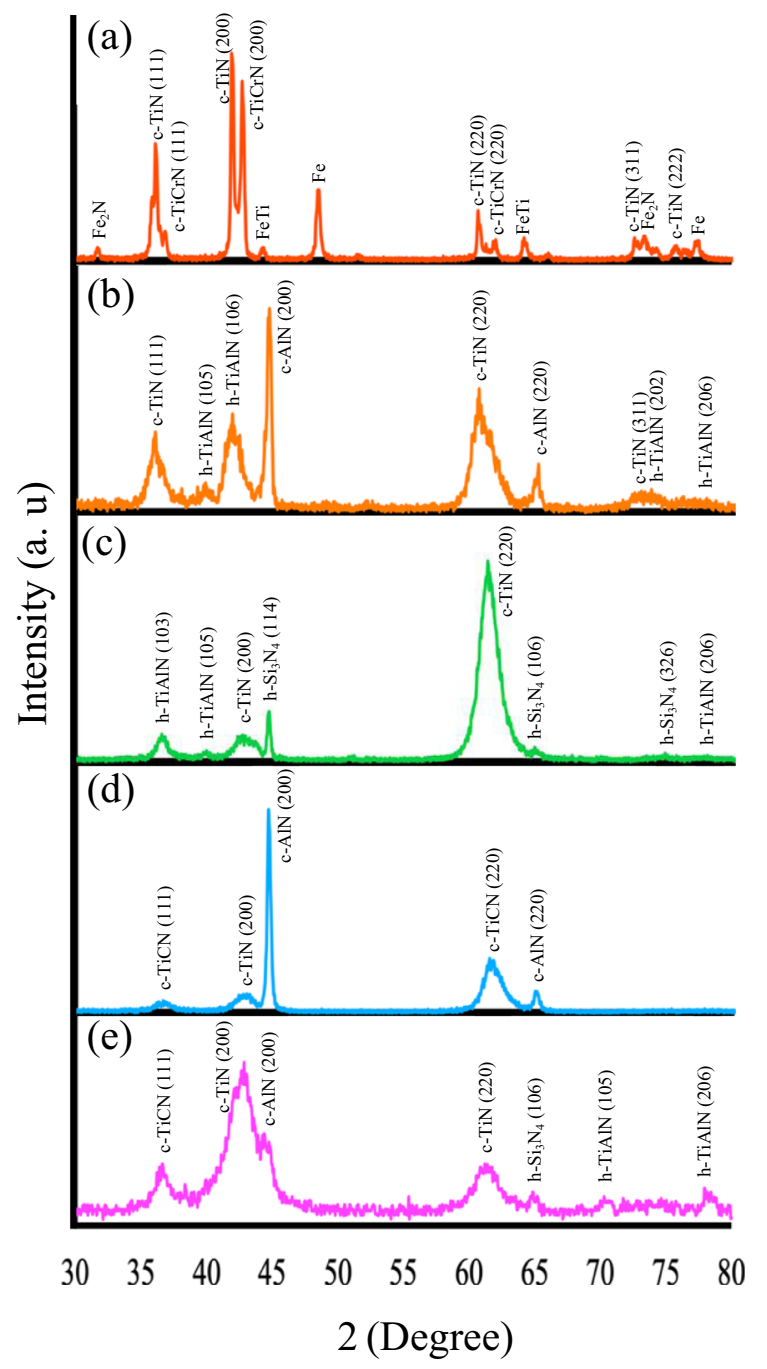

Figure 1. XRD data of (a) TiCrN, (b) TiAlN, (c) TiAlSiN, (d) TiAlSiCN single layers, and (e) the multi-layer.

and their distribution throughout all the layers. The data in Fig. 3 indicates that the deposition of all the respective layers at $400^{\circ} \mathrm{C}$ was carried out well enough to form hard ceramic layers.

SEM. Figure 4 shows the blades along with SEM images which illustrate surface morphology of the deposited layers before and after the experiment. Image of the TiCrN-TiAlN-TiAlSiN-TiAlSiCN multi-layer surface of the coated blade is shown in bottom corner of Fig. 4b. The cross-section SEM image (Fig. 4a) shows the thickness of each individual layer. TiCrN layer is approximately $2.2 \mu \mathrm{m}$ thick, and TiAlN thickness is $\sim 0.48 \mu \mathrm{m}$. The two last layers TiAlSiN and TiAlSiCN at the top, have a whole thickness of around $1.44 \mu \mathrm{m}$. The reason that the two last layers cannot be distinguished from each other is the resolution of the SEM instrument. However, the line scan analysis in Fig. 3 confirms the formation of all the layers. After the experiment took place, the surface morphology of all the samples were investigated. The optical image of the blades in the bottom corners of Fig. $4 \mathrm{~b}-\mathrm{f}$ reveals that only the top layer which is TiAlSiCN with dark gray color has been worn off. The last sample, which traveled $8 \mathrm{~km}$, clearly shows that the deposited layers perfectly resist to wear under the hard-rocky soil conditions.

Hardness. The hardness measurement was carried out by a Vickers hardness monitor. The hardness of the 4.2 $\mu$ m-thick TiCrN-TiAlN-TiAlSiN-TiAlSiCN multi-layer was measured to be $32.2 \mathrm{GPa}$ with $15 \mathrm{~g}$ applied weight. The hardness of each individual layer alone was $23.7 \mathrm{GPa}$ for TiCrN, 25.8 GPa for TiAlN, 34.6 GPa for TiAlSiN, and 36.4 GPa for TiAlSiCN.

Roughness. 3D AFM and 2D profilometer surface roughness investigations were conducted, both before and after the blades were examined in the field. Figure 5 shows the moving average (purple lines) of the profiles along with their roughness arithmetical mean deviation $\left(R_{a}\right)$, roughness root mean squared $\left(R_{q}\right)$, maximum valley depth $\left(R_{v}\right)$, maximum peak height $\left(R_{p}\right)$ and maximum height of the profile $\left(R_{t}\right)$, which determines the approximate thickness of the layer (Table 1$)^{64}$. These parameters are defined as follows: 

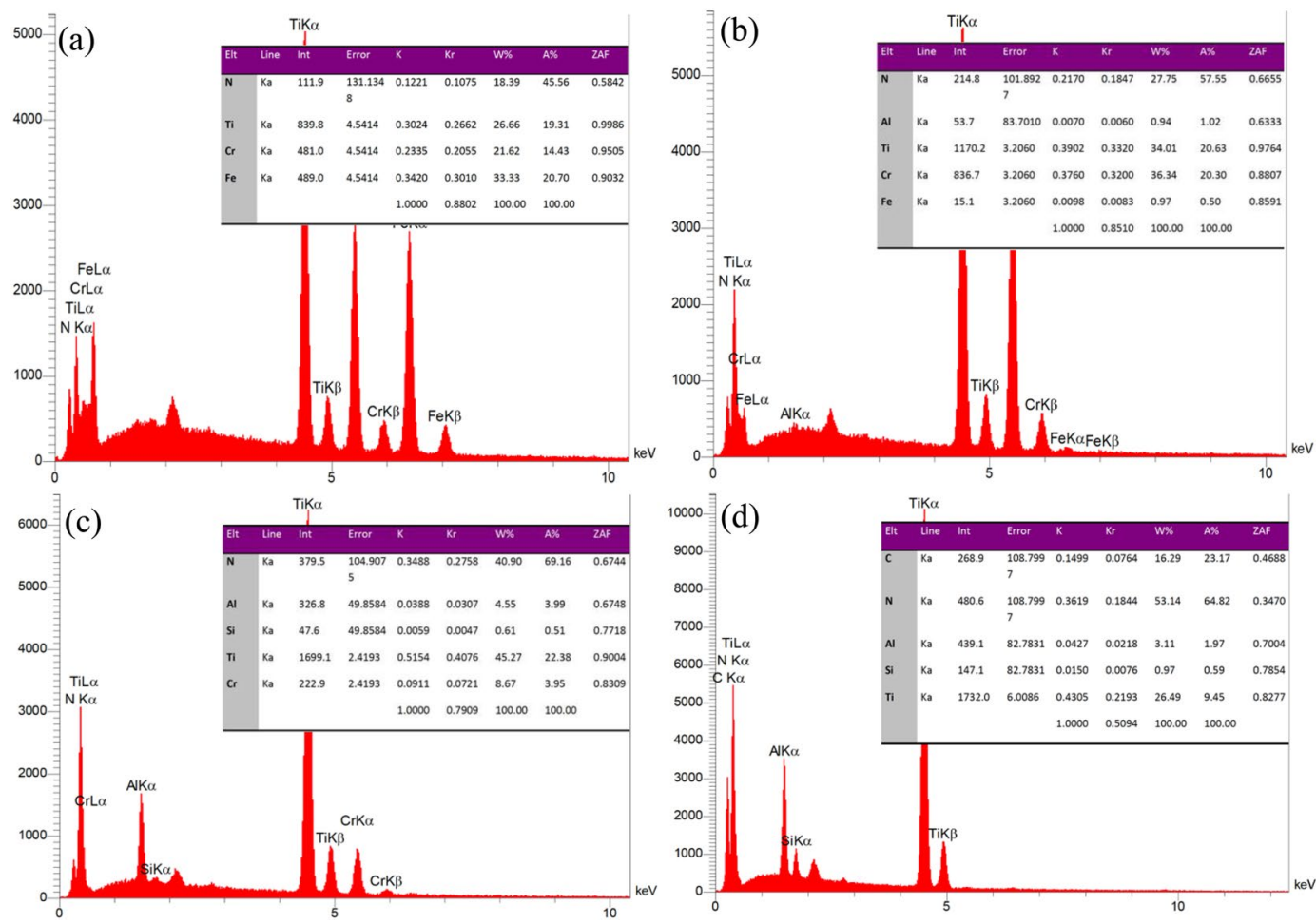

Figure 2. EDX spectra of (a) TiCrN, (b) TiAlN, (c) TiAlSiN and (d) TiAlSiCN layers in the multi-layer.

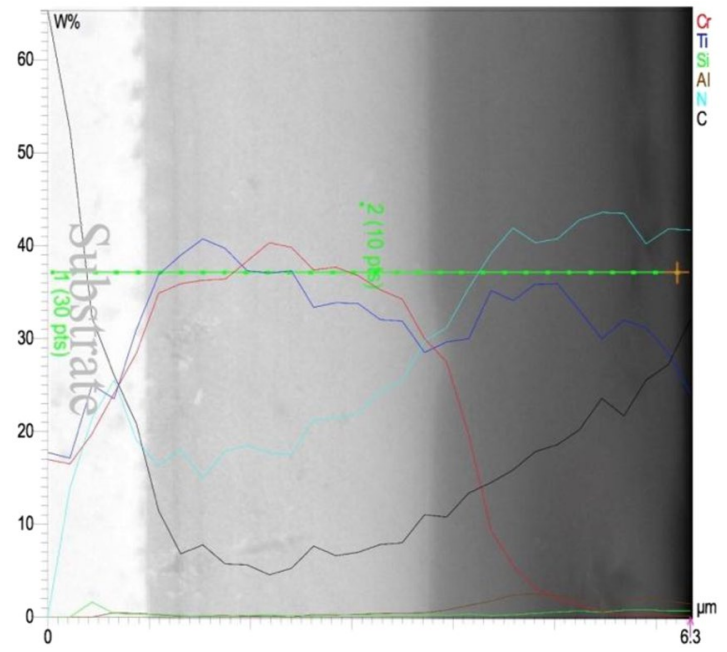

Figure 3. EDX line scan of the multi-layer.

$$
\begin{gathered}
R_{a}=\frac{1}{n} \sum_{i=1}^{n}\left|y_{i}\right| \\
R_{q}=\sqrt{\frac{1}{n} \sum_{i=1}^{n} y_{i}^{2}} \\
R_{v}=\min _{i} y_{i}
\end{gathered}
$$




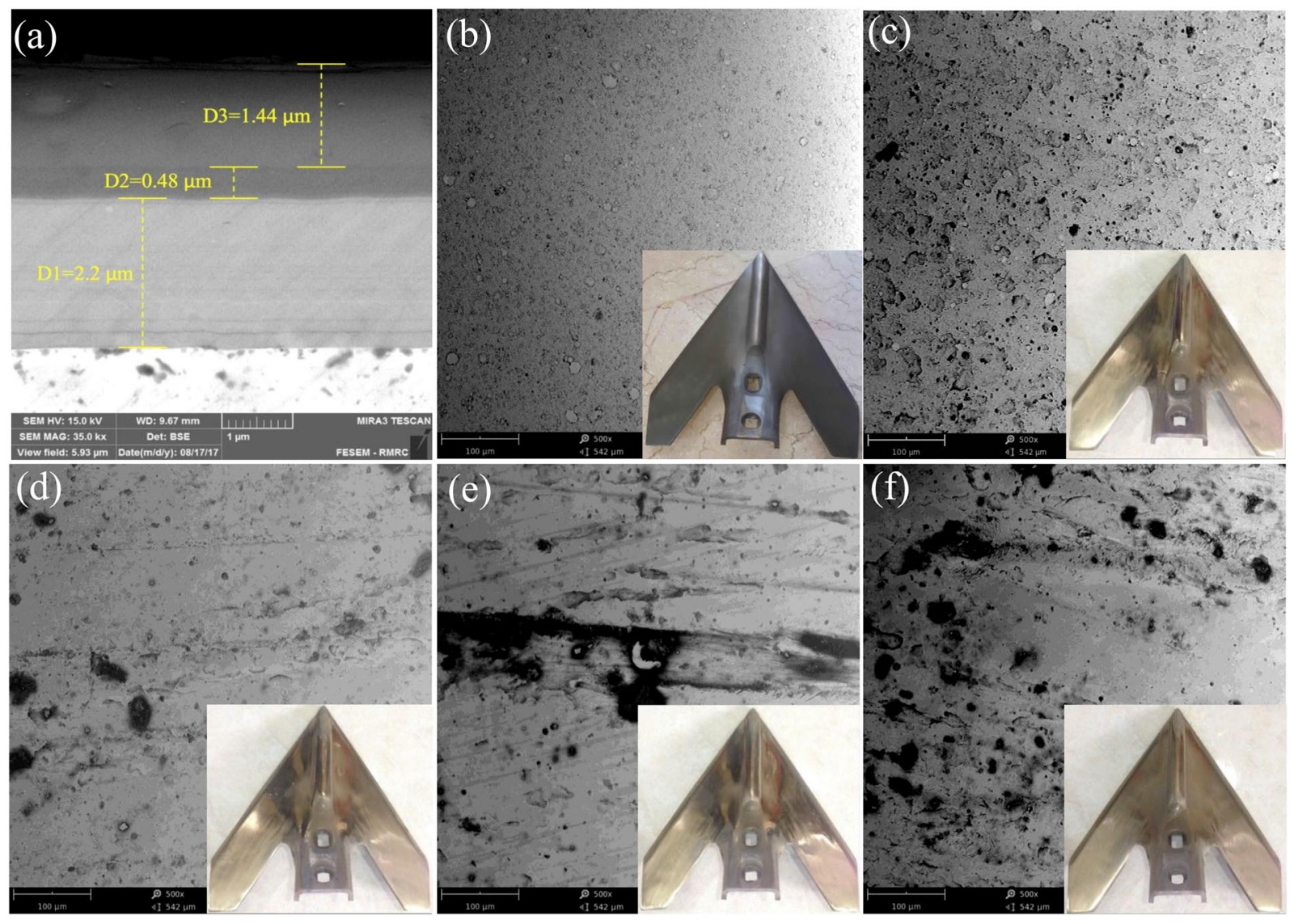

Figure 4. SEM images of the samples before and after the experiment. (a) SEM cross-sectional image of the layers deposited on a polished sample. (b) The surface topography of the coated sample before the experiment. Other figures represent the SEM images of the samples that traveled (c) $2 \mathrm{~km},(\mathbf{d}) 4 \mathrm{~km},(\mathbf{e}) 6 \mathrm{~km}$, and (f) $8 \mathrm{~km}$.

$$
\begin{gathered}
R_{p}=\max _{i} y_{i} \\
R_{t}=R_{p}+R_{v}
\end{gathered}
$$

Draft force and duncan's test. The mean values of draft force of the blades at various distances obtained from the experiment conducted in a soil bin are presented in Fig. 6. These values are corresponded to coated and uncoated blades. The standard deviations of the means are also given to show the mean variations of the data of draft forces. Although the draft forces of coated blades at $0 \mathrm{~km}$ (before file experiments) and $2 \mathrm{~km}$ distances is more than that of uncoated ones but the coated blades caused less draft force than uncoated ones with the values of $1.47,1.42$ and $1.39 \mathrm{kN}$ consumed by tractor than uncoated blades at the traveled distances of 4, 6 and $8 \mathrm{~km}$ in an agricultural field, respectively. As the travel distance increases the draft force decreases for multilayers TiCrN-TiAlN-TiAlSiN-TiAlSiCN coated blades. The mean values of draft force should have been statistically analyzed. Therefore, data were analyzed by Duncan's multiple ranges test and the results are given in Fig. 6 . There is no significant difference between the mean values with same letters at $95 \%$ level of confidence (Fig. 6). The results of the variance analysis (ANOVA) ${ }^{65,66}$ is also shown in Table 2 . The effect of distance on draft force was significant. Specifically, the interaction effect of traveled distance and coating was significant $(\mathrm{p}<0.05)$.

\section{Discussion}

The XRD (Fig. 1) data demonstrated that the arc-PVD method without the need of post-annealing was successful in forming crystallites of c-TiN, c-TiCrN, c-TiCN, and c-AlN along with two hexagonal structures of h-TiAlN and h-Si ${ }_{3} \mathrm{~N}_{4}$. c-TiN (200) peak was detected in all layers but its intensity decreased as c-AlN and h- $\mathrm{Si}_{3} \mathrm{~N}_{4}$ formed in the other layers. This can be the result of the formation of polycrystalline $\mathrm{h}-\mathrm{Si}_{3} \mathrm{~N}_{4}$ in the third layer (Fig. 1c) and amorphous $\mathrm{Si}_{3} \mathrm{~N}_{4}$ in the fourth layer (Fig. 1d) This is similar to results obtained by chen et al. ${ }^{8}$. In their TiAlSiN layer c-TiN peak intensity was reduced due to the presence of $\mathrm{Si}$ and the formation of amorphous $\mathrm{Si}_{3} \mathrm{~N}_{4}$. The most intense peak belonging to TiN (200), showed in Fig. 1 was seen in Wei Li's et al. and Peng's et al. research $^{29,67}$. As well as the mentioned structures, h-TiAlN formed without post-annealing (Fig. 1b). In the work conducted by Endrino et al..$^{40}$, in which TiAlN thin films were deposited by a cathodic arc implanting method, both hexagonal and cubic phases of AlN and cubic TiN crystallites were obtained upon post-annealing and no 


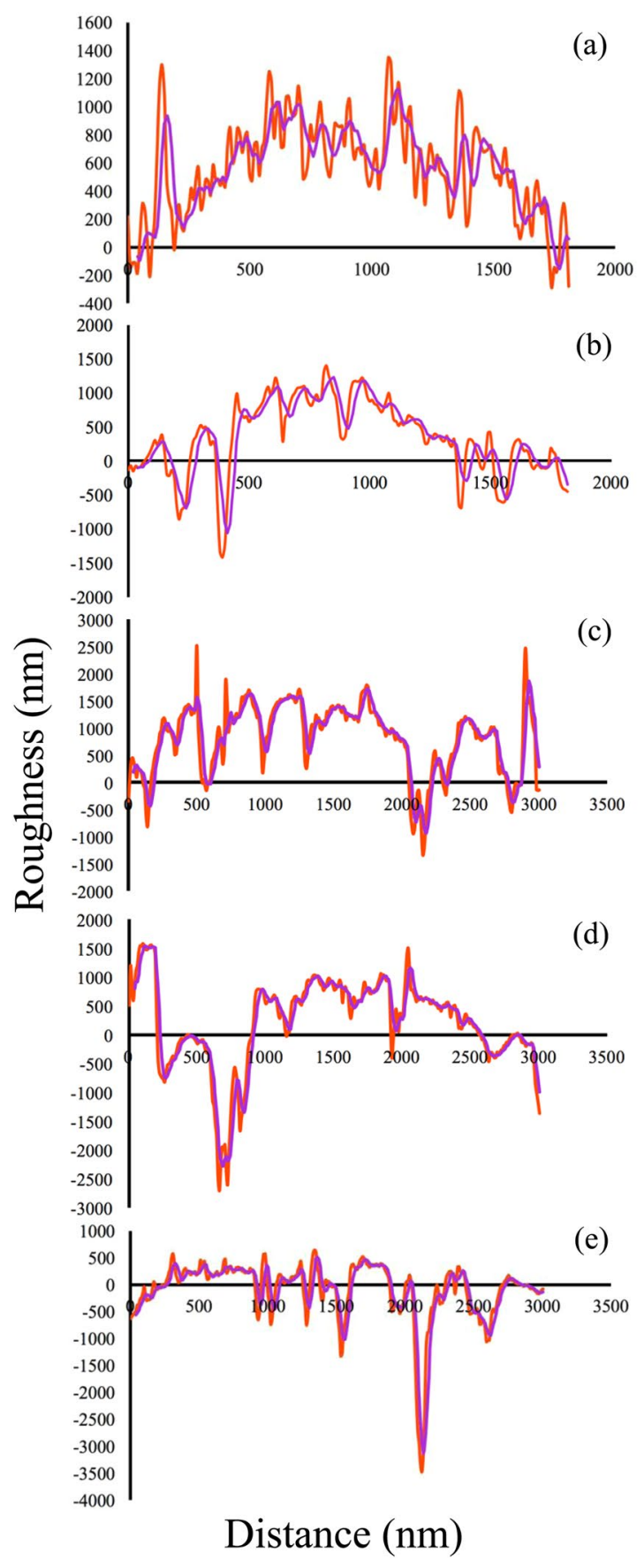

Figure 5. Surface profile of the coated samples before and after the experiment. The orange line stands for the profile and the purple line displays the profile moving average (a) before experiment and for (b) $2 \mathrm{~km},(\mathbf{c}) 4 \mathrm{~km}$, (d) $6 \mathrm{~km}$ and (e) $8 \mathrm{~km}$ traveled blades.

\begin{tabular}{|l|l|l|l|l|l|}
\hline $\begin{array}{l}\text { Distance } \\
(\mathbf{k m})\end{array}$ & $\mathbf{0}$ & $\mathbf{2}$ & $\mathbf{4}$ & $\mathbf{6}$ & $\mathbf{8}$ \\
\hline $\mathrm{R}_{\mathrm{a}}(\mathrm{nm})$ & 211 & 182 & 357 & 576 & 231 \\
\hline $\mathrm{R}_{\mathrm{q}}(\mathrm{nm})$ & 4167 & 3866 & 8637 & 7863 & 3473 \\
\hline $\mathrm{R}_{\mathrm{v}}(\mathrm{nm})$ & -154 & -1052 & -933 & -1537 & -505 \\
\hline $\mathrm{R}_{\mathrm{p}}(\mathrm{nm})$ & 1125 & 1227 & 1858 & 1537 & 505 \\
\hline $\mathrm{R}_{\mathrm{t}}(\mathrm{nm})$ & 1279 & 2280 & 2792 & 3822 & 3638 \\
\hline STDEV & 345 & 551 & 654 & 779 & 573 \\
\hline
\end{tabular}

Table 1. Profilometer measurements of the blades before and after the field experiment. 


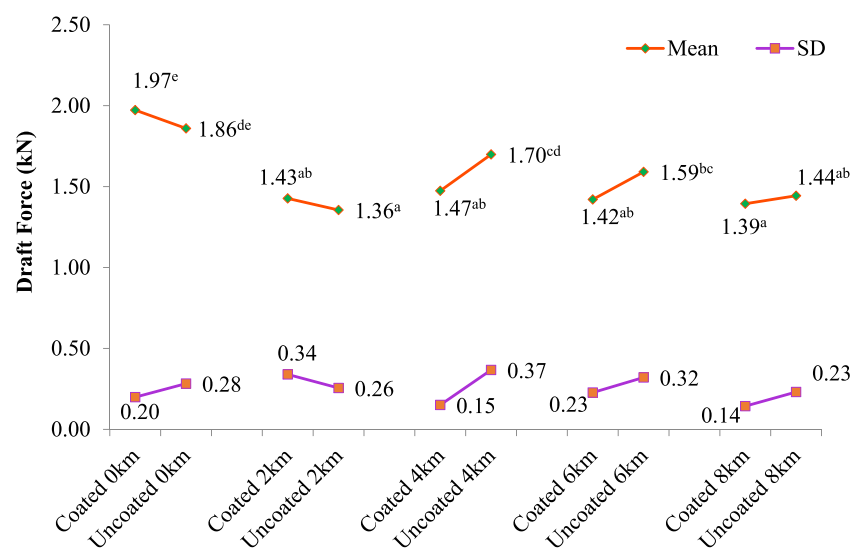

Figure 6. The draft force of the coated and uncoated blades at travelled distances of $0,2,4,6$ and $8 \mathrm{~km}$.

\begin{tabular}{|l|c|l|l|l|l|}
\hline Source & $\begin{array}{l}\text { Sum of } \\
\text { square }\end{array}$ & df & $\begin{array}{l}\text { Mean } \\
\text { square }\end{array}$ & F & Sig \\
\hline Model & $74.551^{\mathrm{a}}$ & 10 & 7.455 & 680.414 & 0.000 \\
\hline Travelled distance & 1.078 & 4 & 0.270 & 24.600 & 0.000 \\
\hline Coating & 0.017 & 1 & 0.017 & 1.577 & 0.224 \\
\hline $\begin{array}{l}\text { Travelled } \\
\text { distance } \times \text { Coating }\end{array}$ & 0.135 & 4 & 0.034 & 3.078 & 0.040 \\
\hline Error & 0.219 & 20 & 0.011 & & \\
\hline Total & 74.770 & 30 & & & \\
\hline
\end{tabular}

Table 2. ANOVA table of coated and uncoated blades data. ${ }^{\mathrm{a}} \mathrm{R}$ Squared $=0.997$ (Adjusted R Squared $=0.996$ ).

exact detection of TiAlN structure became possible. This approves of the fine quality of the layers obtained at low temperature by the arc-PVD method and illustrates that the arc-PVD method has advantages to other methods that need post-annealing at high temperatures. The XRD data observed in Xudong Sui, et al. attempt ${ }^{7}$ at depositing TiAlN-TiAlSiN by reactive magnetron sputtering method at $400^{\circ} \mathrm{C}$ had TiAlN (111) peaks which were not similar to the peaks observed in Fig. 1b,c.

It is notable that in comparison with single layers, the crystallite size for all structures has been reduced in the multi-layer and only c-TiCN and h-TiAlN crystallite sizes have been increased. As the results show, the crystallite sizes have also reduced by the presence of $\mathrm{Si}$ and $\mathrm{Al}$ atoms in the TiAlN, TiAlSiN, and TiAlSiCN thin films. The same issue was reported in previous study where the reason for crystallite size reduction was discussed to be due to the presence of amorphous $\mathrm{SiN}_{\mathrm{x}}$ in TiAlSiN thin films ${ }^{10}$. It is notable that in recent attempts on the growth of TiN-based layers ${ }^{7,9,14}$ XRD patterns were different with much less intense peaks than the data in Fig. 1 which was deposited by an arc-PVD. Furthermore, the XRD spectra of our samples (Fig. 1d,e) have no similarity to that of the TiAlSiCN layer deposited which was by a DC magnetron sputtering and annealed at high temperature in Kuptsov's et al. study ${ }^{27}$.

The SEM image of the surface of the coated blade before the experiment exhibited a uniform deposited layer (Fig. 4b). As the resistance to wear of the samples was tested (Fig. 4c) at $2 \mathrm{~km}$, inhomogeneous layers that had carbon began to wear off. Going forward toward the beneath layers we observed that the homogeneous hard layers of TiAlSiN and TiAlN withstood the wear test with only a few worn off sections at 4 to $8 \mathrm{~km}$ (Fig. $4 \mathrm{~d}-\mathrm{f}$ ). It is of importance to note that only small sections on the tips and edges of the blades wore off and the main body revealed high resistance to wear as shown in the optical images of the all blades in Fig. 4. Comparison of SEM images in Fig. 4 to samples that were annealed after deposition in other studies such as, the work performed by Golizadeh et al. ${ }^{6}$ is notable. Kuptsov et al. in a research on TiAlSiCN layers which were deposited by a DC magnetron sputtering and annealed at high temperatures ${ }^{52}$, could not obtain uniform stacked layers like the ones grown by using the arc-PVD method in our study (Fig. 4). Moreover, the images were taken after the experiment had shown much better results than those of the research conducted by Nalbant ${ }^{26}$ and also our previous research ${ }^{1}$, where a single TiN layer was used to incearse the lifetime of sweep duck blades. The TiCrN-TiAlN-TiAlSiN-TiAlSiCN multi-layers resulted in a much better and improved performance than the TiN layers which were applied to tillage blades ${ }^{1,26}$. While the TiN layers, which were deposited by a PVD method, totally wore off at a distance of around $4 \mathrm{~km}$ in Noblbant's et al. studies ${ }^{26}$, in our experiment the arc-PVD layers did not wear off even after $8 \mathrm{~km}$ traveling distance on the farm. It is obvious that TiN-based arc-PVD coatings in this research have shown advantages to the layers, deposited by other created techniques.

$\mathrm{R}_{\mathrm{a}}$ of the multi-layer deposited by the arc-PVD was obtained $35 \mathrm{~nm}$ by the AFM while other studies reported it about $32 \mathrm{~nm}^{51}$ and $25 \mathrm{~nm}^{52}$ for TiAlSiCN single layer coatings. Thickness reduction and an increase in roughness of all samples were observed after the field experiment. The SEM cross-section image calculated the overall thickness to be $4.2 \mu \mathrm{m}$ (Fig. 4a). Thus, the thickness reduction (worn layer) of each sample after the experiment 


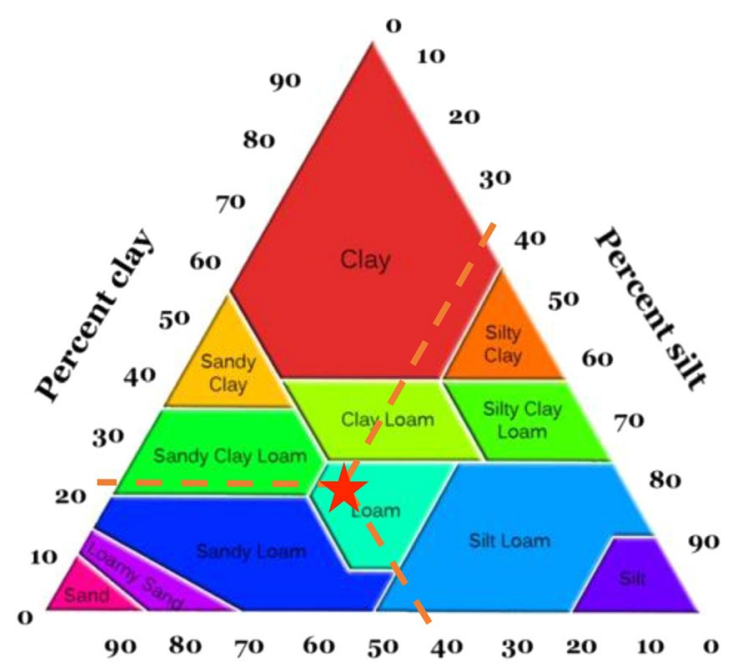

Percent sand

Figure 7. Soil texture triangle.

\section{CI (MPa)}

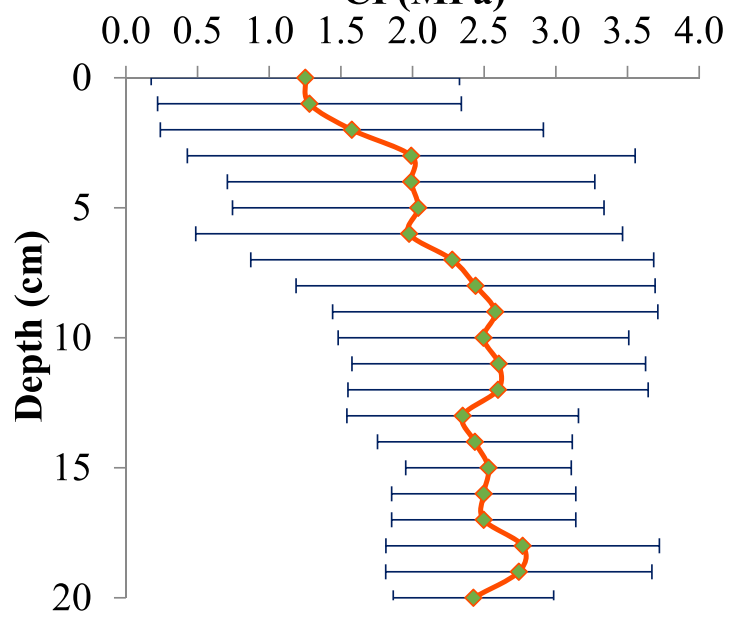

Figure 8. Soil mechanical resistance of the field (CI).

can be calculated by subtracting the overall thickness from $\mathrm{R}_{\mathrm{t}}$. Table 1 shows that $\mathrm{R}_{\mathrm{t}}$ of the sample traveled $2 \mathrm{~km}$ was about $2280 \mathrm{~nm}$. This indicates that the worn layer was approximately $1720 \mathrm{~nm}$. It can be concluded that TiAlSiCN layer nearly wore off after $2 \mathrm{~km}$ travelling. For the samples that traveled 4,6 , and $8 \mathrm{~km}$, the worn layer was measured to be $\sim 1208 \mathrm{~nm}, \sim 178 \mathrm{~nm}$, and $\sim 362 \mathrm{~nm}$ (Table 1), concluding that the resistance to wear of the samples were higher as the traveled distance was increased. Practically, the layers with high hardness showed high resistance to wear on the field.

The hardness of our arc-PVD-deposited multi-layer sample with no post-annealing procedure at $32.2 \mathrm{GPa}$ was comparable to the hardness of the layers created by Golizadeh et al. ${ }^{6}$. They obtained their hard TiAlSiCN layers at $\sim 22 \mathrm{GPa}$ by post-annealing at high temperatures. In another report made by Bondarev et al. ${ }^{53}$, they could achieve TiAlSiCN single layers with hardness of about 41 to $49 \mathrm{GPa}$ by vacuum post-annealing at $1000^{\circ} \mathrm{C}$.

Numerous researches regarding coating tillage tools have been conducted by different scientists. Some of which have used various coating material to investigate their impact on wear rate, useful lifetime and draft force, i.e. TiN, Nickle, chromium, aluminum, and plastic compounds for coating tillage tools. We discuss the results of previous works relevant to the effect of coatings on draft force of tillage tools confirming the results of the present study in this section. Nickel-based alloy powder was used for coating sweep blades to investigate its impact on draft force in a soil bin by Kushwaha et al. Draft force of the blades reduced by $15 \%$ in comparison with the uncoated blades ${ }^{54}$ and ${ }^{68}$. Other research works have shown decrement on draft force acting on the coated tillage tools. For example, new hard facing materials (carbon nanotube-hard chromium composite coated on tillage tools caused $43.29 \%$ reduction on draft force of tools ${ }^{69}$. In comparison with the previous works as mentioned above, our work also demonstrated in agreement with the other studies reduction of averagely $9 \%$ in draft force of the coated 

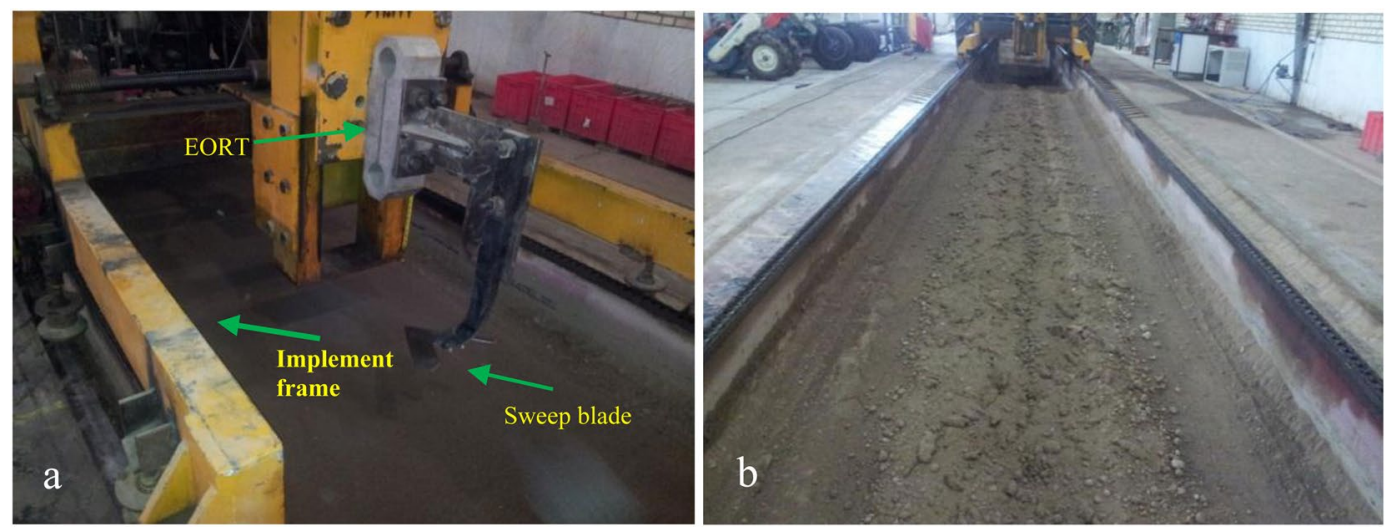

Figure 9. Extended octagonal ring transducer (EORT) (a) used for measuring draft force of sweep blade in the soil bin (b).

blades compared to uncoated ones at 4, 6 and $8 \mathrm{~km}$ distances. In this case, TiCrN-TiAlN-TiAlSiN-TiAlSiCN multi-layers have impacted the blades draft force significantly as they have reduced draft force after $4 \mathrm{~km}$ along with the wear resistance and useful lifetime increment.

\section{Experimental Methods and Conditions}

A cathodic arc evaporation PVD (JHDI/Quad/01 arc-PVD Sevin Plasma Surface Engineering Co.) was used to deposit TiCrN-TiAlN-TiAlSiN-TiAlSiCN multi-layers on carbon steel CK45 substrates (sweep duck blades). Four sweep duck blades were sandblasted with $\mathrm{Al}_{2} \mathrm{O}_{3}$ to sweep away the paint on manufactured painted sweep duck blades. Subsequently, the blades were polished. The samples were heated up to $400{ }^{\circ} \mathrm{C}$ in a vacuum pressure of $10^{-5} \mathrm{mbar}$ in the arc-PVD chamber. After the substrates reached the intended temperature, $99.999 \%$ nitrogen gas $\left(\mathrm{N}_{2}\right)$ was inserted into the chamber that increased its pressure to $10^{-3} \mathrm{mbar}$. The coating targets, $99.9 \% \mathrm{Ti}$ and 99.9\% Cr were biased up to $40 \mathrm{~V}$ and the deposition was undergone for $80 \mathrm{~min}$ to form TiCrN thin film. Following the TiCrN layer formation of about $2.2 \mu \mathrm{m}$, the chamber was cleaned with argon (Ar) gas. The second phase of the deposition began with the same working gas $\left(\mathrm{N}_{2}\right)$, vacuum pressure, biasing voltage, and deposition time, but in this stage for the formation of the second layer a 99.9\% $\mathrm{TiAl}$ ( $\mathrm{Ti} 50 \%, \mathrm{Al} 50 \%$ ) target was used. For the deposition of the third layer, TiAlSiN after the cleaning procedure by Ar gas, the samples were coated using $99.9 \% \mathrm{TiAl}(\mathrm{Ti}$ $50 \%, \mathrm{Al} \mathrm{50 \% )}$ and AlSi (Al 80\%, Si 20\%) targets with the same conditions mentioned in the first 2 stages. Finally, for the fourth layer, TiAlSiCN, the same targets and conditions as the third stage were utilized but in order to add carbon to TiAlSiN, a mixture of methane $\left(\mathrm{CH}_{4}\right)$ and $\mathrm{N}_{2}\left(\mathrm{CH}_{4} 50 \%, \mathrm{~N}_{2} 50 \%\right)$ was inserted as working gas.

A combined tillage tool equipped with the sweep duck blades was used for the field experiments. Experiments were conducted in an agricultural field located at $51^{\circ} 6^{\prime}$ longitude and $35^{\circ} 59^{\prime}$ latitude. Soil samples were taken from the experiment field to measure its soil moisture content and soil chemical properties. These properties were measured by a Biochrom Libra S22 spectrophotometer and a Jenway Flame Spectrometer to indicate the sulfate and sodium of the soil. Soil $\mathrm{pH}$ and soil texture were measured by Hana $209 \mathrm{pH}$ meter and a hydrometer. The chemical elements are determined using a burette titration along with a Jenway 4510 conductivity meter to monitor the electrical conductivity (EC) range of the soil. A penetrologger (Eijkelkamp, Netherland) with cone base area of $1 \mathrm{~cm}^{2}$ and a cone apex angle of $60^{\circ}$ was used to measure vertical soil mechanical resistance (soil cone index (CI)). The sweep blades were attached on the tillage tool shanks. An ITMCO 399 tractor was used to pull the tillage tool in the field. The experiment conducted at a soil depth of $15 \mathrm{~cm}$, with a tractor forward speed of $6 \mathrm{~km} / \mathrm{h}$ at four traveling distances of 2, 4, 6 and $8 \mathrm{~km}$. The first blade was taken off at $2 \mathrm{~km}$ traveling distance. Afterward, the second blade was taken off at $4 \mathrm{~km}$, the third blade at $6 \mathrm{~km}$ and eventually, the final fourth blade at $8 \mathrm{~km}$.

In order to perform a set of analysis, samples of $1 \mathrm{~cm}^{2}$ were cut off the blades. An Ara Research NANOVAC atomic force microscopy (AFM) and a Phenom-XL scanning electron microscopy (SEM) was utilized for surface morphology investigations. Normal X-ray diffraction (XRD) and both regional and multi-spot (Line Scan) energy-dispersive X-ray spectroscopy (EDX) (attached to the SEM device) were used for element detections and crystallographic studies. A Vickers Hardness tester was utilized to measure the hardness of the coated layers. The surface roughness measurements were carried out by Nano Pajouhan Raga Surface Profilometer 50.10.s and AFM. The blades draft force was measured in the soil bin ${ }^{70}$, at the depth of $15 \mathrm{~cm}$ and soil conditions similar to the field.

The experimental conditions same as previous study ${ }^{1}$. The soil physical and chemical properties of the experimental field were as given below. The number of total cations was 13.41 milliequivalent/liter $(\mathrm{meq} / \mathrm{lit})\left(\mathrm{Mg}^{2+}=4.5\right.$, $\left.\mathrm{Ca}^{2+}=5.75, \mathrm{Na}^{+}=3.17\right)$ and total anions was $15.41 \mathrm{meq} / \mathrm{lit}\left(\mathrm{HCO}_{3}{ }^{-}=6.25, \mathrm{Cl}^{-}=3.75, \mathrm{SO}_{4}{ }^{-2}=5.41\right)$. Soil electrical conductivity and soil $\mathrm{pH}$ were $1.36 \mathrm{ds} / \mathrm{m}$ and 7.62 , respectively. Soil physical properties including soil texture, moisture content and soil mechanical resistance known as CI were also measured. The percentage of soil particles was $45 \%$ sand, $21 \%$ clay and $34 \%$ silt. The soil texture of the field was then determined as loam according to soil texture triangle $\mathrm{e}^{70,71}$ (Fig. 7). Soil moisture content was $11 \%$. Prior to carrying out the experiments in the field, soil CI was measured using penetrologger to a depth of $20 \mathrm{~cm}$ at 10 insertion points with the distance of $20 \mathrm{~m}$ from each other in the field to obtain the mean CI. The value of cone index increases with the depth of the soil. CI of the soil started from 1.25 MPa on the soil surface and reached to $2.5 \mathrm{MPa}$ at the depth of $20 \mathrm{~cm}$. The soil CI with 
the related variations is depicted in Fig. 8. The field had not been tilled for one year. Stones and crop residues were also observed in the field. A hard soil condition was chosen to test the blades at the harshest environment.

A soil bin equipped with an extended octagonal ring transducer $(E O R T)^{72}$, which is attached to an implement frame, is shown in Fig. 9. The EORT was used to measure the draft force of the sweep duck blades at $15 \mathrm{~cm}$ depth in the soil with the moisture content of $12 \%$. The forward speed of the blades was $6 \mathrm{~km} / \mathrm{h}$. The optimum length of the soil bin was $9 \mathrm{~m}$. The influence of the blades wear on the draft force was also investigated. Experimental design of factorial test based on the randomized complete design (RCD) was employed to perform the experiments. Two factors of traveled distance at five levels of $0,2,4,6$ and $8 \mathrm{~km}$ of both coated and uncoated blades with three replications were used for statistical analysis of draft force data. The mean draft force is compared with Duncan multiple range test at $95 \%$ level of confidence by SPSS statistical software (ver. 22).

\section{Conclusion}

The multi-layers of TiCrN, TiAlN, TiAlSiN, and TiAlSiCN with the thickness of $4.2 \mu \mathrm{m}$ have been deposited on CK45 carbon steel for performance improvement of tillage tools (duck blades). The arc-PVD method was able to apply high-quality layers to the samples with no need for post-annealing at high temperatures (XRD and EDX data supported this statement). The sweep blades were tested at both the lab (soil bin) and on the field to investigate their resistance to wear and draft force. With the comparison of the SEM cross-sectional image and the profilometer roughness the worn layers were calculated for most of the samples to be only about $\sim 100 \mathrm{~nm}$. The soil bin draft force experiment showed an increase of draft force as the coated layers wore off after $2 \mathrm{~km}$ distance. All in all, tillage tool blades resistance to wear, use full lifetime where increased due to the use of TiCrN-TiAlN-TiAlSiN-TiAlSiCN multi-layer coatings. This operation improvements are owned to the application of arc-PVD technique in deposition of hard multi-layer.

Received: 26 August 2019; Accepted: 29 November 2019;

Published online: 13 December 2019

\section{References}

1. Sharifi Malvajerdi, S., Sharifi Malvajerdi, A. \& Ghanaatshoar, M. Protection of CK45 carbon steel tillage tools using TiN coating deposited by an arc-PVD method. Ceramics International 45, 3816-3822 (2019).

2. Kuptsov, K. A., Kriyukhantsev-Korneev, P. V., Sheveyko, A. N. \& Shtansky, D. V. Comparative study of electrochemical and impact wear behavior of TiCN, TiSiCN, TiCrSiCN, and TiAlSiCN coatings. Surface and Coatings Technology 216, 273-281 (2013).

3. Shtansky, D. V. et al. Comparative investigation of Al- and Cr-doped TiSiCN coatings. Surface and Coatings Technology 205, 4640-4648 (2011).

4. Wei, R. Plasma enhanced magnetron sputter deposition of Ti-Si-C-N based nanocomposite coatings. Surface and coatings technology 203, 538-544 (2008).

5. Mikula, M. et al. Toughness enhancement in highly NbN-alloyed Ti-Al-N hard coatings. Acta Materialia 121, 59-67 (2016).

6. Gholizadeh, M., Kuptsov, K. A., Shvyndina, N. V. \& Shtansky, D. V. Multilayer SiBCN/TiAlSiCN and AlOx/TiAlSiCN coatings with high thermal stability and oxidation resistance. Surface and Coatings Technology 319, 277-285 (2017).

7. Sui, X. et al. Relationship of microstructure, mechanical properties and titanium cutting performance of TiAlN/TiAlSiN composite coated tool. Ceramics International 42, 7524-7532 (2016).

8. Chen, T., Xie, Z., Gong, F., Luo, Z. \& Yang, Z. Correlation between microstructure evolution and high temperature properties of TiAlSiN hard coatings with different Si and Al content. Applied Surface Science 314, 735-745 (2014).

9. Xiao, B. et al. Effects of microstructure evolution on the oxidation behavior and high-temperature tribological properties of AlCrN/ TiAlSiN multilayer coatings. Ceramics international 44, 23150-23161 (2018).

10. Liu, H. et al. Effect of modulation structure on the microstructural and mechanical properties of TiAlSiN/CrN thin films prepared by high power impulse magnetron sputtering. Surface and coatings technology 358, 577-585 (2019).

11. Kumar, C. S. \& Patel, S. K. Effect of duplex nanostructured TiAlSiN/TiSiN/TiAlN-TiAlN and TiAlN-TiAlSiN/TiSiN/TiAlN coatings on the hard turning performance of Al2O3-TiCN ceramic cutting tools. Wear 418-419, 226-240 (2019).

12. Li, G. et al. Microstructure, mechanical properties, and cutting performance of TiAlSiN multilayer coatings prepared by HiPIMS. Surface and coatings technology 353, 274-281 (2018).

13. Durmaz, Y. M. \& Yildiz, F. The wear performance of carbide tools coated with TiAlSiN, AlCrN and TiAlN ceramic films in intelligent machining process. Ceramics international 45, 3839-3848 (2019).

14. Gao, F., Li, G. \& Xia, Y. Influence of hysteresis effect on properties of reactively sputtered TiAlSiN films. Applied Surface Science 431, 160-164 (2018)

15. Kumar, C. S. \& Patel, S. K. Performance analysis and comparative assessment of nano-composite TiAlSiN/TiSiN/TiAlN coating in hard turning of AISI 52100 steel. Surface and coatings technology 335, 265-279 (2018).

16. Shizhi, L., Yulong, S. \& Hongrui, P. Ti-Si-N films prepared by plasma-enhanced chemical vapor deposition. Plasma Chem \& Plasma Process 12(3), 287-297 (1992).

17. Bechelany, M. C. et al. In Situ Controlled Growth of Titanium Nitride in Amorphous Silicon Nitride: A General Route Toward Bulk Nitride Nanocomposites with Very High Hardness. Advanced Materials 36(38), 6548-6553 (2014).

18. Hetmanczyk, M., Swadzba, L. \& Mendala, B. Advanced materials and protective coating in aero-engine application. Journal of Achievements in Materials and Manufactruing Engineering 24(1), 372-381 (2007).

19. Swadzba, L. et al. Influence of coatings obtained by PVD on the properties of aircraft compressor blades. Surface and coatings technology 78(1-3), 137-143 (1996).

20. Hedenqvist, P. et al. How TiN coatings improve the performance of high speed steel cutting tools. Surface and Coatings Technology 41(2), 243-256 (1990).

21. Carvalho, S. et al. Microstructure, mechanical properties and cutting performance of superhard (Ti,Si,Al)N nanocomposite films grown by d.c. reactive magnetron sputtering. Surface and coatings technology 177-178, 459-468 (2004).

22. He, J. L., Chen, C. K. \& Hon, M. H. Wear of Ti-Si-N coated ceramic cutting inserts. Wear 181-183, 189-193 (1995).

23. Zhang, C. H. et al. Microstructure, mechanical properties, and oxidation resistance of nanocomposite Ti-Si-N coatings. Applied Surface Science 252, 6141-6153 (2006).

24. Urbanski, J. P., Koshy, P., Dewes, R. C. \& Aspinwall, D. K. High speed machining of moulds and dies for net shape manufacture. Materials \& Design 21(4), 395-402 (2000).

25. Spakale, P. R., Tiwari, G. \& Sharma, A. K. Influence of surface hardening processes on wear characteristics of soil working tools- a review. International Journal of Engineering Science and Emerging Technologies 8(4), 191-201 (2016). 
26. Nalbant, M. \& Tufan Palali, A. Effects of different material coatings on the wearing of plowshares in soil tillage. Turk J Agric for 35, 215-223 (2011).

27. Kuptsov, K. A., Kiryukhantsev-Korneev, P. V., Sheveyko, A. N. \& Shtansky, D. V. Structural transformations in TiAlSiCN coatings in the temperature range $900-1600^{\circ} \mathrm{C}$. Acta Materialia 83, 408-418 (2015).

28. Xu, H., Nie, X. \& Wei, R. Tribological behavior of TiSiCN coating tested in air and coolant. Surface and Coatings Technology 201(7), 4236-4241 (2006).

29. Li, W. et al. Microstructures, mechanical behavior and strengthening mechanism of TiSiCN nanocomposite films. Scientific reports 7(2140), 1-10 (2017).

30. Bartosik, M., Rumeau, C., Hahn, R., Zhang, Z. L. \& Mayrhofer, P. H. Fracture toughness and structural evolution in the TiAlN system upon annealing. Scientific Reports 7(16476), 1-9 (2017).

31. Ou, Y. X. et al. Microstructure and tribological behavior of TiAlSiN coatings deposited by deep oscillation magnetron sputtering. Journal of the American ceramic society 101, 5166-5176 (2018).

32. Persson, P. O. A., Kodambaka, S., Petrov, I. \& Hultman, L. Epitaxial Ti2AlN( $\left.\begin{array}{llll}0 & 0 & 0 & 1\end{array}\right)$ thin film deposition by dual-target reactive magnetron sputtering. Acta Materialia 55, 4401-4407 (2007).

33. Keckes, J. et al. Self-organized periodic soft-hard nanolamellae in polycrystalline TiAlN thin films. Thin Solid Films 545, 29-32 (2013).

34. Jin, Z., Li, P. \& Xiao, D. Enhanced Electrocatalytic Performance for Oxygen Reduction via Active Interfaces of Layer-By-Layered Titanium Nitride/Titanium Carbonitride Structures. Scientific Reports 4, 6712 (2014).

35. Li, Y. S., Shimada, S., Kiyono, H. \& Hirose, A. Synthesis of Ti-Al-Si-N nanocomposite films using liquid injection PECVD from alkoxide precursors. Acta Materialia 54, 2041-2048 (2006)

36. Wang, L., Huang, L., Xie, Z., Wang, X. \& Tang, B. Fourth-generation plasma immersion ion implantation and deposition facility for hybrid surface modification layer fabrication. Rev. Sci. Instrum 79, 023306 (2008).

37. Xie, Z. W. et al. Microstructure and tribological properties of diamond-like carbon and TiAlSiCN nanocomposite coatings. Surface and coatings technology 206, 1293-1298 (2011).

38. Omrani, M., Habibi, M. \& Birjandi, M. S. M. Enhanced electrical conductivity of two layers AlN-TiN coating on SS316L as bipolar plate using plasma focus device. International journal of hydrogen energy 41, 5028-5036 (2016).

39. Jianxin, D., Fengfang, W., Yunsing, L., Youqiang, X. \& Shipeng, L. Erosion wear of CrN, TiN, CrAlN, and TiAlN PVD nitride coatings. International Journal of Refractory Metals and Hard Materials 35, 10-16 (2012).

40. Endrino, J. L. et al. Spectral evidence of spinodal decomposition, phase transformation and molecular nitrogen formation in supersaturated TiAlN films upon annealing. Acta Materialia 59, 6287-6396 (2011).

41. Rousseau, A. F. et al. Microstructural and tribological characterisation of a nitriding/TiAlN PVD coating duplex treatment applied to M2 High Speed Steel tools. Surface and coatings technology 272, 403-408 (2015).

42. N. Norrby, L. RogstrÖm, M.P. Johansson-JÕesaar, N. Schell, M. Odé n. In situ X-ray scattering study of the cubic to hexagonal transformation of AlN in Til $-x \mathrm{Al} x \mathrm{~N}$. Acta Materialia, 73:205-214, (2014).

43. I.C. Schramm, M.P. Johansson Jo esaar, J. Jensen, F. Mücklich, M. Oden Impact of nitrogen vacancies on the high temperature behavior of (Ti1-xAlx)Ny alloys. Acta Materialia, 119:218-228, (2016).

44. Xu, Y. X., Chen, L., Pei, F., Chang, K. K. \& Du, Y. Effect of the modulation ratio on the interface structure of TiAlN/TiN and TiAlN/ $\mathrm{ZrN}$ multilayers: First-principles and experimental investigations. Acta Materialia 130, 281-288 (2017).

45. Yu, D., Wang, C., Cheng, X. \& Zhang, F. Microstructure and properties of TiAlSiN coatings prepared by hybrid PVD technology. Thin Solid Films 517, 4950-4955 (2009).

46. Moskal, G., Goral, M., Swadzba, L., Mendala, B. \& Jarczyk, G. Characterization of TiAlSi Coating Deposited by Arc-PVD Method on TiAlCrNb Intermetallic Base Alloy. Defect and Diffusion Forum 237-240, 1153-1156 (2005).

47. Bujak, J., Walkowicz, J. \& Kusinski, J. Influence of the nitrogen pressure on the structure and properties of (Ti, Al)N coatings deposited by cathodic vacuum arc PVD process. Surface and Coatings Technology 180-181, 150-157 (2004).

48. Fox-Rabinovich, G. et al. Spatio-temporal behaviour of atomic-scale tribo-ceramic films in adaptive surface engineered nanomaterials. Scientific Reports 5, 8780 (2015).

49. I. Povstugar, Pyuck-Pa Choi, D. Tytko, Jae-Pyeong Ahn, D. Raabe Interface-directed spinodal decomposition in TiAlN/CrN multilayer hard coatings studied by atom probe tomography. Acta Materialia, 61:7534-7542, (2013).

50. Schramm, I. C. et al. Solid state formation of Ti4AlN3 in cathodic arc deposited (Ti1-xAlx)Ny alloys. Acta Materialia 129, 268-277 (2017).

51. Xie, Z. W. et al. Influence of high temperature annealing on the structure, hardness and tribological properties of diamond-like carbon and TiAlSiCN nanocomposite coatings. Applied Surface Science 258, 1206-1211 (2001).

52. Kuptsov, K. A., Kiryukhantsev-Korneev, P. V., Sheveyko, A. N. \& Shtansky, D. V. Surface modification of TiAlSiCN coatings to improve oxidation protection. Applied Surface Science 347, 713-718 (2015).

53. Bondarev, A. V., Kiryukhantsev-Korneev, P. V. \& Shtansky, D. V. Hard wear-resistant TiAlSiCN/MoSeC coatings with a low friction coefficient at room and elevated temperatures. Russian Journal of Non-Ferrous Metals 56, 107-113 (2015).

54. Kushwaha, R. L., Chi, L. \& Roy, C. Investigation of agricultural tools with plasma-sprayed coatings. Tribology International 23, 297-300 (1990).

55. Jia, X. \& Ling, X. Reduction of soil resistance through the use of a composite coating. JCT Research 2, 669-672 (2005).

56. Foley, A. G., Lawton, P. J., Barker, A. W. \& Mclees, V. A. The use of alumina ceramic to reduce wear of soil-engaging components. J. agric. Engng Res 30, 37-46 (1984).

57. Bayhan, Y. Reduction of wear via hardfacing of chisel ploughshare. Tribology International 39, 570-574 (2006).

58. Kravchenko, I., Kuznetsov, Y., Bobryashov, E. \& Kolomeichenko, A. Plasma restoration and hardening of elements of tillage tools. Scientific Journal of Agricultural Engineering 4, 91-99 (2014).

59. Kolomeichenko, A. V. \& Titov, N. V. Investigation of hardness of tillage tools being hardened by carbo-vibro-arc method with paste application. Vestnik OrelGAU 51, 96-101 (2014).

60. Yazici, A. Investigation of the reduction of mouldboard ploughshare wear through hot stamping and hardfacing processes. Turk J Agric For 35, 461-468 (2011).

61. Holzwarth, U. \& Gibson, N. The Scherrer equation versus the 'Debye-Scherrer equation'. Nature Nanotechnology 6, 534 (2011).

62. Hans, M. et al. Crystallite size-dependent metastable phase formation of TiAlN coatings. Scientific Reports 7, 16096 (2017).

63. Ahmadi, M., Asemi, M. \& Ghanaatshoar, M. Improving the electrical and optical properties of $\mathrm{CuCrO} 2$ thin film deposited by reactive RF magnetron sputtering in controlled N2/Ar atmosphere. Applied Physics A 124, 529 (2018).

64. Heinemann, B. Surfaces and their measurement. Ebook ISBN: 9780080950679 (2004).

65. Duncan, D. B. Multiple Range and Multiple F Tests. Biometrics 11(1), 1-42 (1955).

66. Permanasari, A. E., Rambil, D. R. A. \& Dominic, P. D. D. Forecasting method selection using ANOVA and Duncan multiple range tests on time series dataset. 2010 International Symposium on Information Technology (2010).

67. Peng, Z., Miao, H., Qi, L., Yang, S. \& Liu, C. Hard and wear-resistant titanium nitride coatings for cemented carbide cutting tools by pulsed high energy density plasma. Acta Materialia 51, 3085-3094 (2003).

68. Zein El-Din, A. M. \& Saad, F. A. and R. G. Abdel Hamied, Alex. Effect of new hard facing materials of tillage tools on draft and roughness. J. Agric. Sci 61(3), 243-251 (2016).

69. Zhang, J. \& Kushwaha, R. L. Wear and draft of cultivator sweeps with hardened edges. Can. Agricu. Eng. 37(1), 41-47 (1995). 
70. Sharifi, A. Comparison of cone and prismatic tips for measuring soil mechanical resistance by a horizontal sensor. Agricultural Engineering International: CIGR. Journal 18, 66-72 (2016).

71. https://courses.lumenlearning.com/geo/chapter/reading-soil-texture-and-composition

72. Godwin, R. J. An extended octagonal ring transducer for use in tillage studies. J. Agric. Eng. Res. 20, 347-352 (1975).

\section{Acknowledgements}

The authors would like to acknowledge the Iran National Science Foundation (INSF) for funding of this project (No. 95813100). The Agricultural Engineering Research Institute (Karaj, Iran), is acknowledged for its help in soil analysis and providing of the experimental field along with the soil bin. Moreover, thanks to Dr. Homa Behmadi for her assistance on statistical analysis of draft force data.

\section{Author contributions}

S. Sharifi Malvajerdi wrote the article and proposed the idea and carried out all the experiments from deposition to analysis. A. Sharifi Malvajerdi supervised the project and was granted by INSF to perform this project, he carried out all agricultural experiments along with data processing and also wrote the agricultural machinery sections of the article. M. Ghanaatshoar and M. Habibi helped with writing and revising the article and gave advice on the processing of the material science-based analysis. H. Jahdi helped with the deposition of the materials with his arc-PVD instrument and he carried out the hardness and XRD analysis.

\section{Competing interests}

The authors declare no competing interests.

\section{Additional information}

Correspondence and requests for materials should be addressed to A.S.M.

Reprints and permissions information is available at www.nature.com/reprints.

Publisher's note Springer Nature remains neutral with regard to jurisdictional claims in published maps and institutional affiliations.

(c) (i) Open Access This article is licensed under a Creative Commons Attribution 4.0 International License, which permits use, sharing, adaptation, distribution and reproduction in any medium or format, as long as you give appropriate credit to the original author(s) and the source, provide a link to the Creative Commons license, and indicate if changes were made. The images or other third party material in this article are included in the article's Creative Commons license, unless indicated otherwise in a credit line to the material. If material is not included in the article's Creative Commons license and your intended use is not permitted by statutory regulation or exceeds the permitted use, you will need to obtain permission directly from the copyright holder. To view a copy of this license, visit http://creativecommons.org/licenses/by/4.0/.

(C) The Author(s) 2019 